\title{
Solution Heat treatment, Forming and in-die Quenching of a commercial sheet magnesium alloy into a complex-shaped component: experimentation and FE simulation
}

\author{
O. El Fakir ${ }^{1, a}$, S. Das ${ }^{2}$, I. Stone ${ }^{2}$, G. Scamans ${ }^{2}$, Z. Fan ${ }^{2}$, L. Wang ${ }^{1}$, D. Balint ${ }^{1}$, \\ J. P. Dear ${ }^{1}$ and J. Lin ${ }^{1, b}$ \\ ${ }^{1}$ Department of Mechanical Engineering, Imperial College London, SW7 2AZ, UK \\ ${ }^{2}$ The EPSRC Centre - LiME, BCAST, Brunel University, UB8 3PH, UK \\ aoa107@imperial.ac.uk, bjianguo.lin@imperial.ac.uk
}

Keywords: Magnesium alloy, tensile tests, stamping, AZ31, HFQ

\begin{abstract}
Interest in lightweight materials, particularly magnesium alloys, has increased significantly with rising efficiency requirements in the automotive sector. Magnesium is the lightest available structural metal, with a density approximately $35 \%$ lower than that of aluminium. The potential is great for magnesium to become a primary material used in future low carbon vehicle structures; however, there are significant obstacles, namely low ductility and formability, particularly at room temperature. The aim of this work is to present the feasibility of using the solution Heat treatment, Forming, and in-die Quenching (HFQ) process to produce complex shapes from a sheet magnesium alloy, and to use the results to verify a simulation of the process developed using commercial FE software. Uniaxial tensile tests were initially conducted to establish the optimum parameters for forming the part. Stamping trials were then carried out using these parameters, and a simulation set up modelling the forming operation. It was shown that the HFQ process could be used to form a successful component from this alloy, and that a good match was achieved between the results of the forming experiments and the simulation.
\end{abstract}

\section{Introduction}

Transport accounts for a quarter of greenhouse gas emissions in the UK [1]. The government's commitment to reducing UK emissions to a level 80\% below their 1990 baseline [2] has led to increasing pressure on the automotive sector to improve vehicle efficiencies. An effective route to achieving this is lightweighting; a $40 \%$ reduction in curb weight can improve efficiency by up to $30 \%$ [3]. With a density of $1738 \mathrm{~kg} / \mathrm{m}^{3}$, which is approximately $35 \%$ lower than that of aluminium, magnesium is the lightest available structural metal [4]; by expanding its use in vehicle structures it can therefore enable higher efficiencies to be attained.

Currently, magnesium alloys are predominantly used in cast components [5]; their application in formed components has been restricted due to their limited ductility and formability at low temperatures [6]. A deformation temperature of at least $300^{\circ} \mathrm{C}$ is required to form a component from AZ31, one of the most common wrought alloys, particularly if higher forming speeds are to be used [5]. As has been well documented, sufficient ductility in magnesium is only attained at temperatures above $200^{\circ} \mathrm{C}$ due to the thermal activation of further slip systems, while formability is also enhanced due to the increase in the strain rate sensitivity [7-10]. In the past, components have been formed successfully from this alloy using warm and superplastic forming methods [11-13]. However in this work, the novel hot forming process, solution Heat treatment, Forming, and in-die Quenching, or HFQ, is used to form a complex-shaped component at a high rate from AZ31 sheets, acquired from a commercial source.

In the HFQ process, the blank is heated to its solution heat treatment (SHT) temperature, at which it is more ductile and the yield stress is lower [14]. For AZ31, heating the blank at $450^{\circ} \mathrm{C}$ for 1 minute is sufficient for solutionizing to occur, where the solutes and precipitates fully dissolve 
into the $\alpha-\mathrm{Mg}$ matrix [15]. The blank is then formed at a high speed in a cold tool; this ensures that sufficient strain and strain rate hardening occurs to enhance formability, and that there is minimal heat transfer between the blank and tool during forming. Finally, the formed component is quenched by holding it in the cold tool; this minimizes thermal distortion and springback, while providing a high postform strength potential through the formation of a supersaturated solid solution (SSSS) [16, 17].

HFQ has been used for aluminium alloys with great success, and so it is a promising technology for the forming of magnesium alloy components. To assess the feasibility of applying the process to AZ31, the mechanical properties of the material were first characterized through uniaxial tensile tests; the results of these guided the selection of the parameters that were used during forming. A simulation of the process was then developed and validated using the commercial finite element (FE) software package PAMSTAMP.

\section{Experimentation}

Uniaxial tensile tests. Dog-bone shaped specimens were machined using electrical discharge machining (EDM) from the $1.80 \mathrm{~mm}$ thick AZ31 sheet, and tested to failure using a Gleeble 3800 thermo-mechanical testing system. The composition of the material is shown in Table 1, and the geometry of the specimens in Fig. 1.

Table 1: Chemical composition of AZ31 [18]

\begin{tabular}{ccccc}
\hline Element & $\mathrm{Al}$ & $\mathrm{Zn}$ & $\mathrm{Mn}$ & $\mathrm{Mg}$ \\
\hline Wt\% & $2.5-3.5$ & $0.7-1.3$ & $0.2-1.0$ & Bal. \\
\hline & & & & \\
\hline
\end{tabular}

Figure 1: Geometry of the tensile test specimens (dimensions in $\mathrm{mm}$ )

The specimens were tested at temperatures between $20^{\circ} \mathrm{C}$ and $450^{\circ} \mathrm{C}$, at constant strain rates of 0.1, 1.0 and 10/s; strain was measured using a C-Gauge, shown in Fig. 2(a). To avoid the possibility of overheating the specimens, they were first heated at a rate of $50^{\circ} \mathrm{C} / \mathrm{s}$ to a temperature $25^{\circ} \mathrm{C}$ below the target temperature, and then heated further at a slower rate of $5^{\circ} \mathrm{C} / \mathrm{s}$ to the target temperature, at which they were soaked for 1 minute; this ensured that the temperature distribution was homogeneous before deformation. The temperature evolution is shown in Fig. 2(b).

(a)

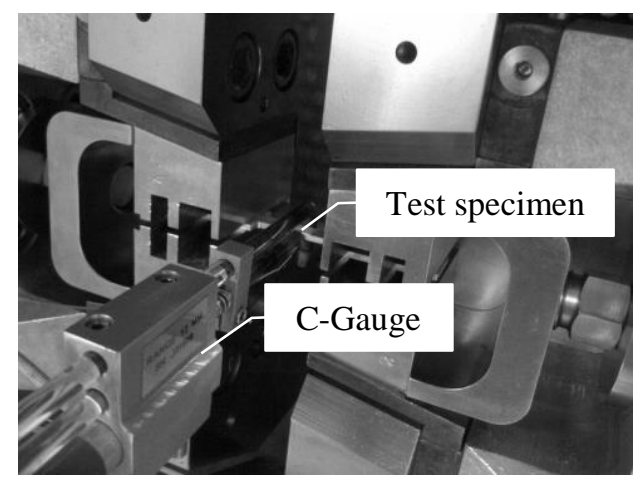

(b)

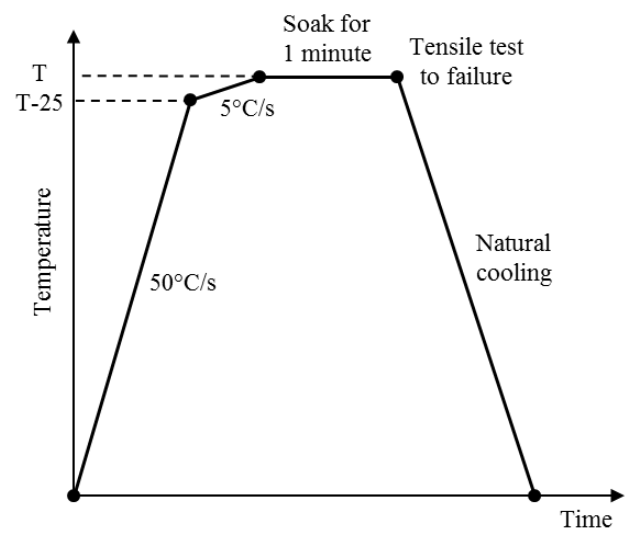

Figure 2: (a) Test specimen setup and (b) test temperature evolution

HFQ tests. HFQ tests were conducted on the alloy using a tool previously manufactured for the production of an aircraft panel, shown in Fig. 3(a) and Fig. 3(b). 
(a)

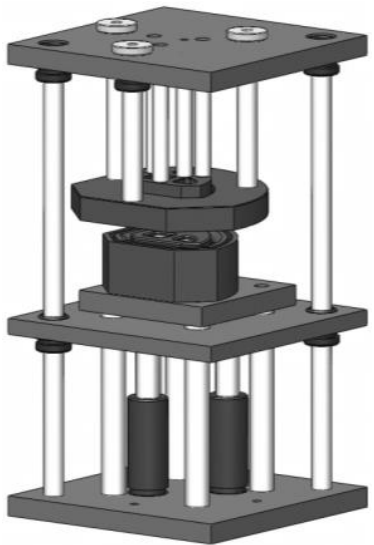

(b)

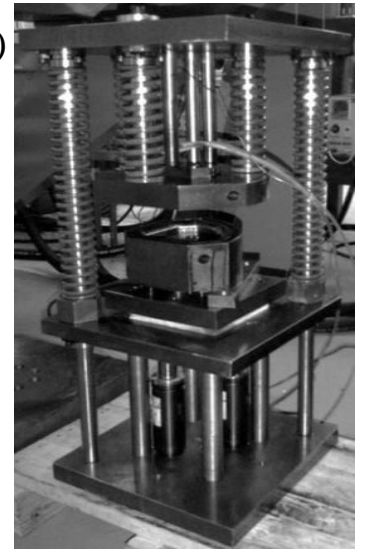

(c)

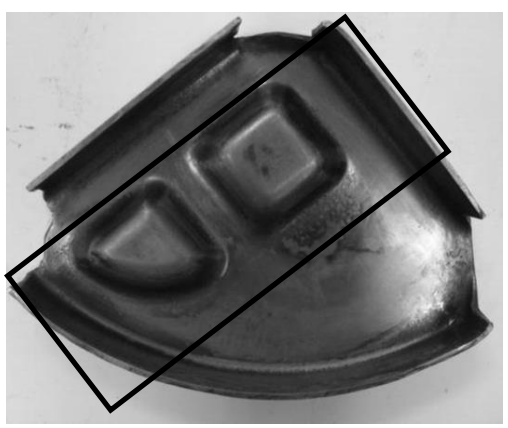

Figure 3: (a) 3D geometry model and (b) photograph of the forming tool, and (c) the component

The tool was mounted on a $250 \mathrm{kN}$ ESH press, which provided the forming load. The blanks were heated in a furnace, and transferred rapidly and carefully to the tool once their target temperature was reached, for forming and subsequent holding and quenching. To avoid complications associated with optimising the blank shape, only a section of the component was formed of dimensions $200 \times 65 \mathrm{~mm}$, highlighted in Fig. 3(c). The results of the uniaxial tensile tests guided the selection of the forming process parameters. A target blank temperature of $450^{\circ} \mathrm{C}$ and a forming speed of $250 \mathrm{~mm} / \mathrm{s}$ were used, appropriate for the HFQ process.

\section{Finite element (FE) simulation}

A finite element (FE) model of the HFQ process was developed in PAMSTAMP, a software package specialized for the simulation of sheet forming operations. CAD models of the relevant parts of the tool geometry were imported to set up the model, shown in Fig. 4.

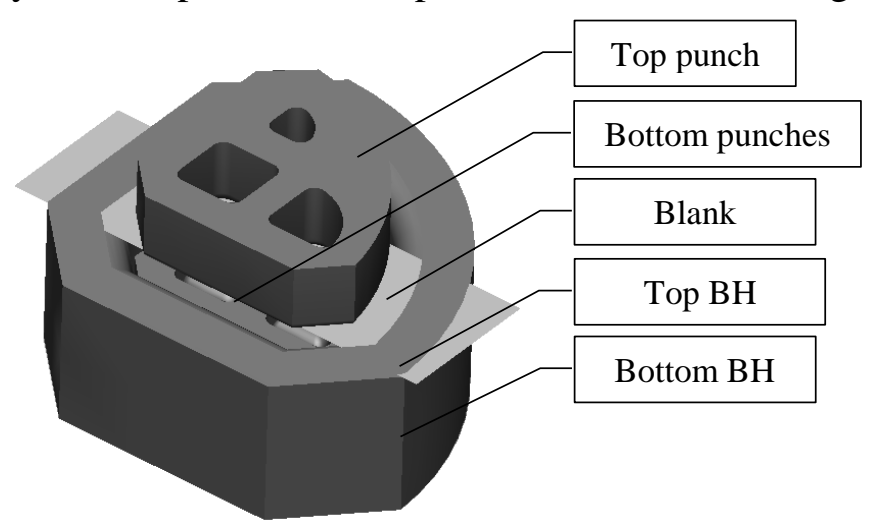

Figure 4: FE model of the forming process

Due to the complex deformation and the anisothermal nature of this forming process, a 3-D, explicit, thermo-mechanical simulation was selected. Belytschko-Tsay shell elements with hourglass control were used for the blank, and surface meshes for the tool parts were generated by the PAMSTAMP DeltaMESH module according to the simulation strategy selected. Table 2 shows the values of the physical properties of AZ31, and Table 3 the FE model parameters, which were used in the simulation. A temperature and strain rate dependent material model for AZ31 was created from the results of the uniaxial tensile tests and implemented in the simulation. 
Table 2: Physical properties of AZ31

\begin{tabular}{lc}
\hline AZ31 physical property & Value \\
\hline Thermal conductivity [W/mK] & 76.9 \\
\hline Specific heat [J/kgK] & 1040 \\
\hline Density[kg/m $\left.{ }^{3}\right]$ & 1780 \\
\hline Poisson's Ratio & 0.35 \\
\hline Young's Modulus [GPa] & 45 \\
\hline
\end{tabular}

Table 3: FE model parameters

\begin{tabular}{lc}
\hline Parameter & Value \\
\hline Tool temperature $\left[{ }^{\circ} \mathrm{C}\right]$ & 20 \\
\hline Blank temperature $\left[{ }^{\circ} \mathrm{C}\right]$ & 450 \\
\hline Forming speed $[\mathrm{mm} / \mathrm{s}]$ & 250 \\
\hline Number of elements for blank & 3250 \\
\hline Friction coefficient & 0.13 \\
\hline Heat transfer coefficient $\left[\mathrm{J} / \mathrm{m}^{2} \mathrm{sK}\right]$ & $46 \times 10^{3}$ \\
\hline
\end{tabular}

\section{Results and discussion}

The results of the uniaxial tensile tests at temperatures between $20^{\circ} \mathrm{C}$ and $450^{\circ} \mathrm{C}$ are shown in Fig. 5(a) for a strain rate of 1/s. AZ31 shows very limited ductility at room temperature, however as the temperature reaches and exceeds $200^{\circ} \mathrm{C}$, ductility begins to improve significantly. As mentioned previously, this has been attributed to the activation of further slip systems. The highest ductility is observed at $450^{\circ} \mathrm{C}$, the SHT temperature of the material, as it results in fewer obstacles to dislocation motion; other researchers have also noted the occurrence of dynamic recrystallisation (DRX) at high temperatures, contributing to the increased ductility [19]. The high true strain values measured from the experiments arises due to the increasing level of necking as the temperature is increased, as shown in Fig. 5(b); this was also reported in [12], but at a strain rate of 0.001/s. This could be due to a very fine initial grain size in the alloy.

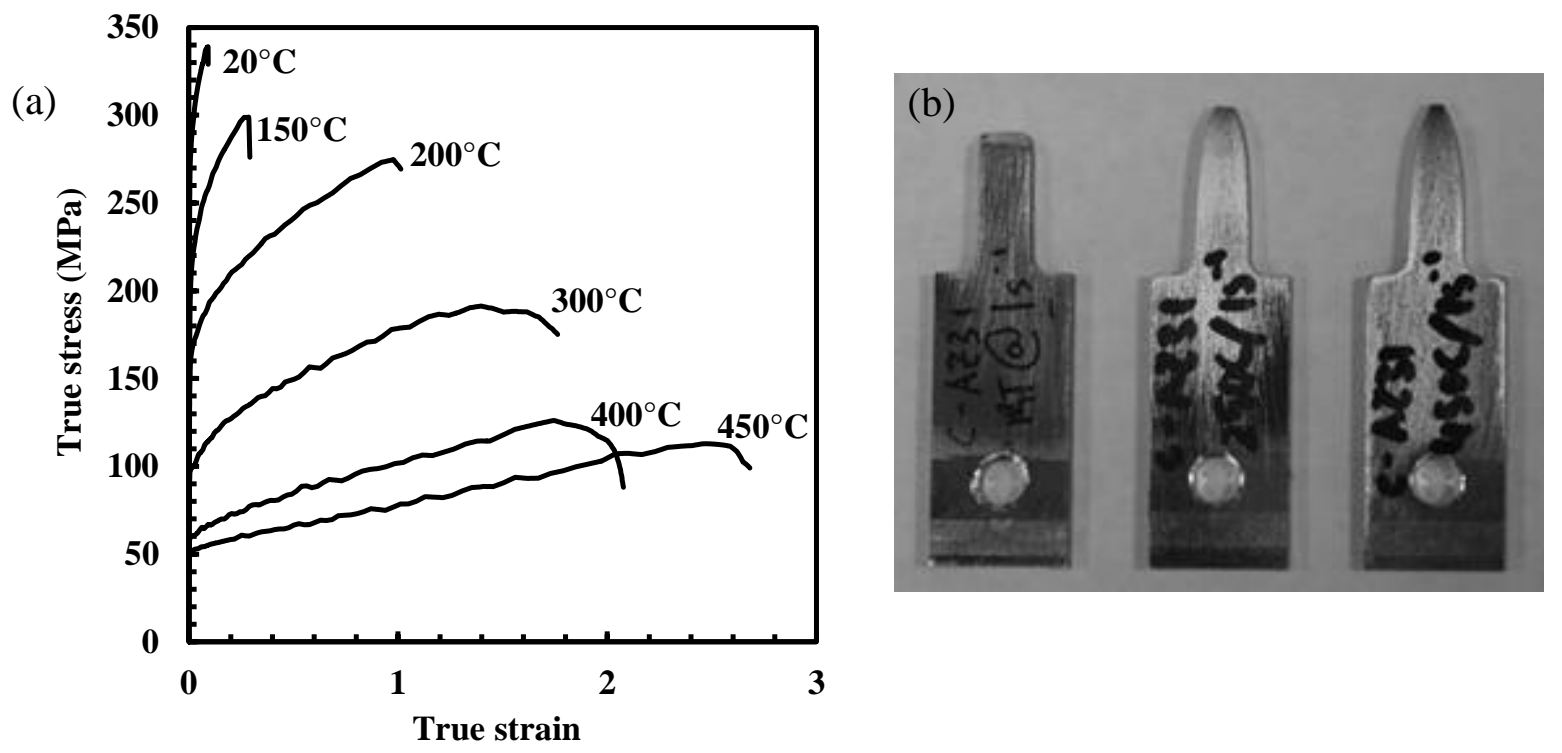

Figure 5: (a) Stress-strain curves for AZ31 at a strain rate of 1/s and (b) photographs of the deformed specimens at, from the left, $20^{\circ} \mathrm{C}, 250^{\circ} \mathrm{C}$ and $450^{\circ} \mathrm{C}$

The uniaxial tensile tests confirmed that a temperature of $450{ }^{\circ} \mathrm{C}$ would be suitable for applying the HFQ process on this alloy. Fig. 6(b) is a photograph of a component successfully formed from AZ31 using HFQ, at a temperature of $450^{\circ} \mathrm{C}$ and speed of $250 \mathrm{~mm} / \mathrm{s}$. Fig. 6(a) shows that it was not 
possible to cold form this alloy into the component. In Fig. 6(c) the results of the simulation developed in PAMSTAMP can be seen; the numerically derived component has an excellent geometric match with the experimentally derived one.

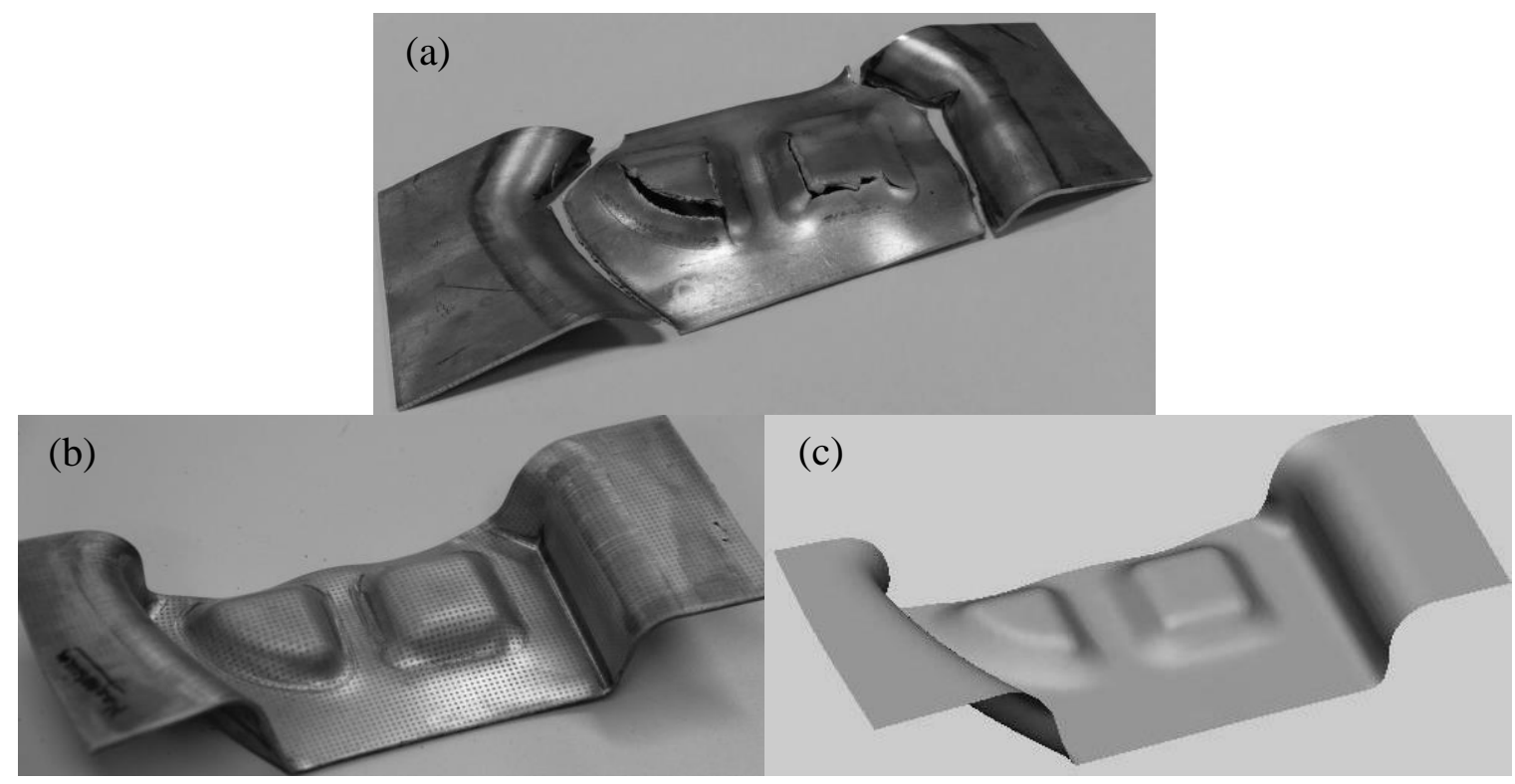

Figure 6: (a) Cold formed and (b) HFQ formed AZ31 component, and (c) simulated component

To conduct a quantitative comparison between the results of the experiment and simulation, optical strain measurement techniques were utilized. Before forming, the AZ31 blank was electrically etched with a regular grid pattern. After forming, photographs at multiple angles and elevations were input into ARGUS, a software package provided by GOM, for analysis; this enabled strain information from the part to be obtained. Fig. 7 shows true thinning contours for the simulated (left), and real component (right); despite some information missing from the real component, good agreement was obtained, with maximum thinning occurring at the corner regions of the central features for both parts.

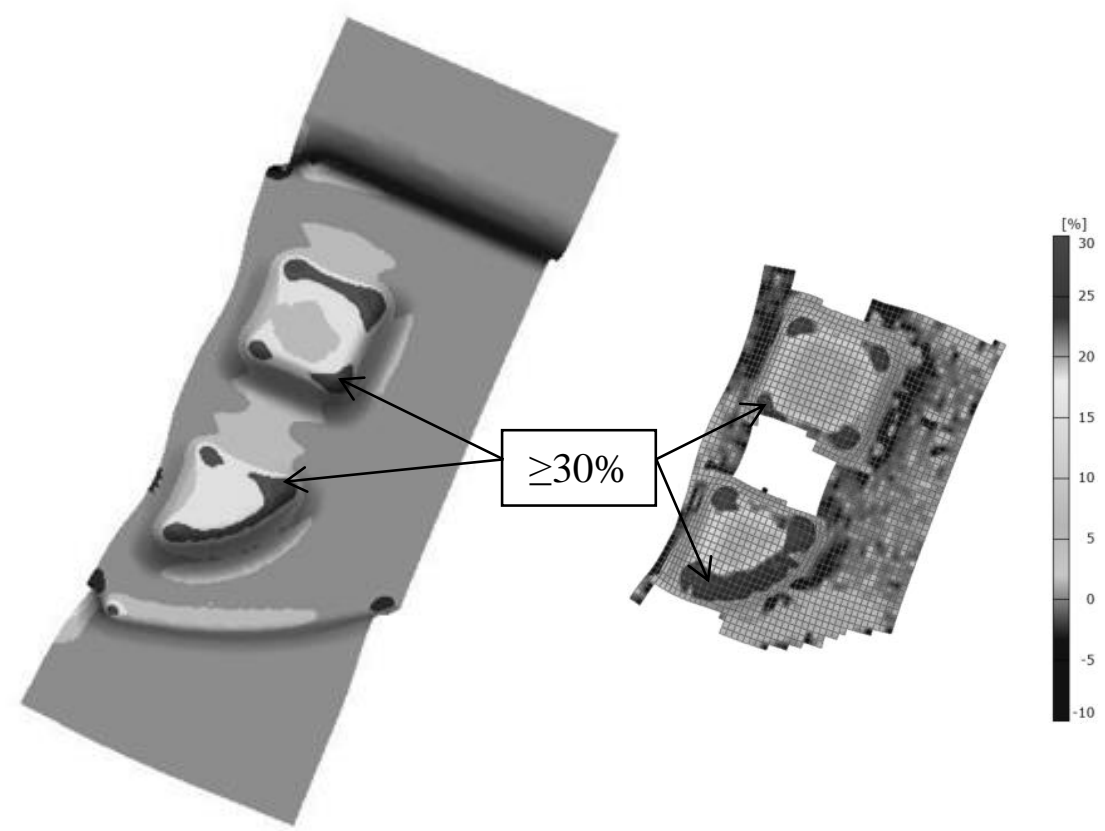

Figure 7: True thinning contours for the simulated (left) and real (right) components

For a more detailed comparison, the major strain distribution across a section of the component (s-s), shown in Fig. 8, was obtained from the simulated and real components. Good agreement was achieved, particularly between the trends in major strain; however deformation at some of the 
corner features was underestimated by the simulation. This would be resolved through the implementation of an alloy-specific material model for AZ31.
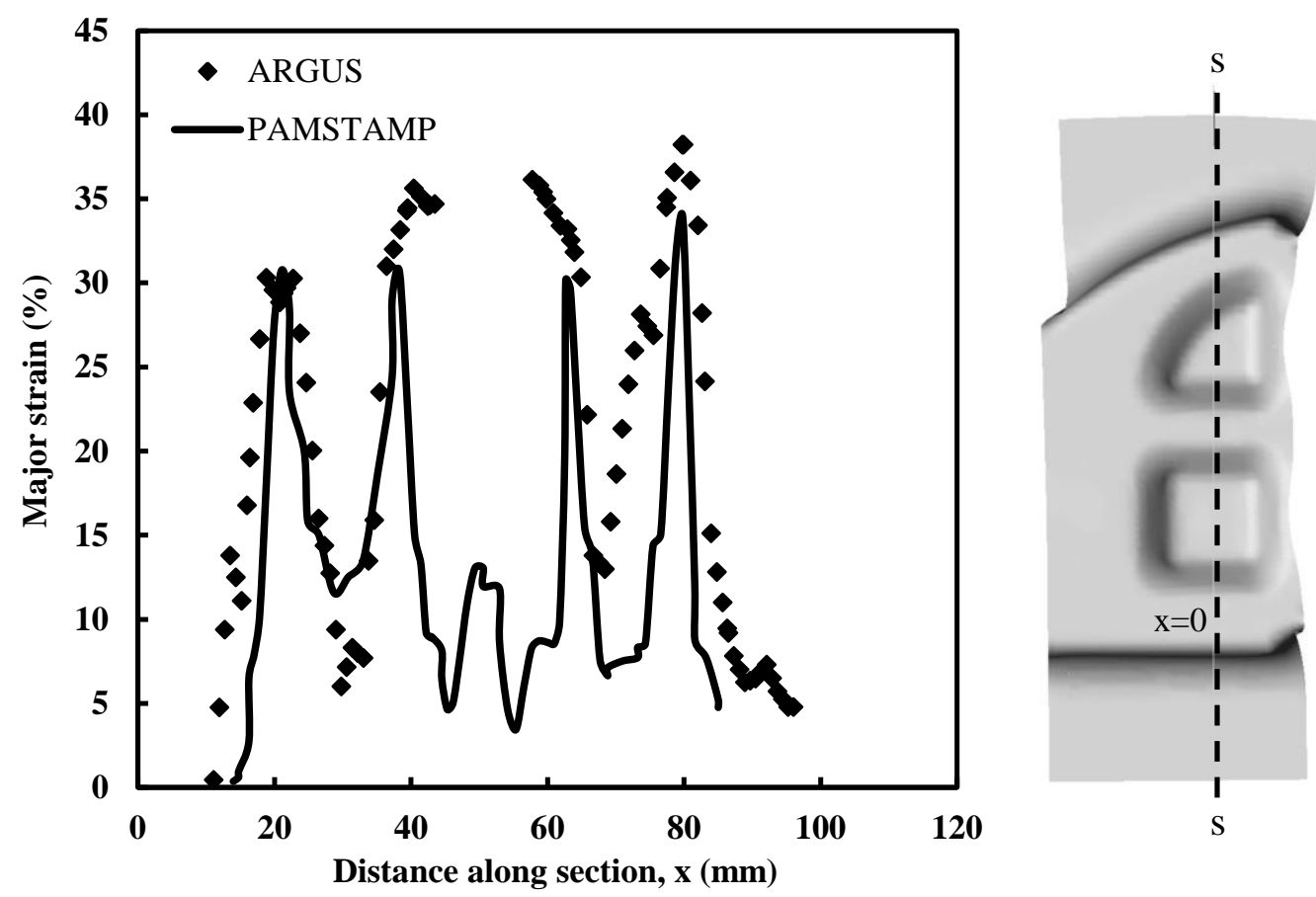

Figure 8: Major strain distribution across a section of the simulated and real components

\section{Summary}

The mechanical properties of AZ31 were characterized to confirm the appropriate forming process parameters before proceeding with HFQ. It was found that AZ31 could be successfully formed into a complex-shaped component using HFQ, at a temperature and speed of $450^{\circ} \mathrm{C}$ and $250 \mathrm{~mm} / \mathrm{s}$ respectively, demonstrating the suitability of the process for forming this alloy. A FE simulation of the process was also developed and verified. Further microstructure analyses will be carried out to better understand the deformation at high temperature and speed. This will also aid in the implementation of a material model for AZ31 to yield more accurate simulation results.

\section{Acknowledgments}

The authors gratefully acknowledge the support from the EPSRC (Grant Ref: EP/I038616/1) for TARF-LCV: Towards Affordable, Closed-Loop Recyclable Future Low Carbon Vehicle Structures.

\section{References}

[1] U.K. Government, 2012 UK greenhouse gas emissions, provisional figures and 2011 UK greenhouse gas emissions, final figures by fuel type and end-user, in, Department of Energy and Climate Change, 2013.

[2] U.K. Government, Climate Change Act, in, 2008.

[3] A. Casadei, R. Broda, Impact of Vehicle Weight Reduction on Fuel Economy for Various Vehicle Architectures, in, Ricardo, 2007.

[4] M.M. Avedesian, H. Baker, Magnesium and Magnesium Alloys, ASM International, Materials Park, Ohio, 1999. 
[5] E. Doege, K. Dröder, S. Janssen, Deformation of Magnesium, in: Magnesium - Alloys and Technology, Wiley-VCH Verlag GmbH \& Co. KGaA, 2004, pp. 72-89.

[6] E. Emley, Principles of Magnesium Technology, Pergamon Press, London, 1966.

[7] R. Verma, L.G. Hector, P.E. Krajewski, E.M. Taleff, The Finite Element Simulation of Hightemperature Magnesium AZ31 Sheet Forming, Jom, 61 (2009) 29-37.

[8] S.R. Agnew, O. Duygulu, Plastic anisotropy and the role of non-basal slip in magnesium alloy AZ31B, Int. J. Plast., 21 (2005) 1161-1193.

[9] I.A. Maksoud, H. Ahmed, J. Rodel, Investigation of the effect of strain rate and temperature on the deformability and microstructure evolution of AZ31 magnesium alloy, Mater. Sci. Eng. AStruct. Mater. Prop. Microstruct. Process., 504 (2009) 40-48.

[10] C.J. Neil, S.R. Agnew, Crystal plasticity-based forming limit prediction for non-cubic metals: Application to Mg alloy AZ31B, Int. J. Plast., 25 (2009) 379-398.

[11] K. Dröder, S. Janssen, Forming of Magnesium Alloys - A Solution for Light Weight Construction, in, SAE International, 1999.

[12] P.E. Krajewski, Elevated Temperature Forming of Sheet Magnesium Alloys, in, SAE International, 2001.

[13] Y.S. Lee, M.C. Kim, S.W. Kim, Y.N. Kwon, S.W. Choi, J.H. Lee, Experimental and analytical studies for forming limit of AZ31 alloy on warm sheet metal forming, J. Mater. Process. Technol., 187 (2007) 103-107.

[14] J. Lin, T.A. Dean, Modelling of microstructure evolution in hot forming using unified constitutive equations, J. Mater. Process. Technol., 167 (2005) 354-362.

[15] M. Marya, L.G. Hector, R. Verma, W. Tong, Microstructural effects of AZ31 magnesium alloy on its tensile deformation and failure behaviors, Mater. Sci. Eng. A-Struct. Mater. Prop. Microstruct. Process., 418 (2006) 341-356.

[16] L. Wang, M. Strangwood, D. Balint, J. Lin, T.A. Dean, Formability and failure mechanisms of AA2024 under hot forming conditions, Mater. Sci. Eng. A-Struct. Mater. Prop. Microstruct. Process., 528 (2011) 2648-2656.

[17] M.S. Mohamed, A.D. Foster, J.G. Lin, D.S. Balint, T.A. Dean, Investigation of deformation and failure features of AA6082: Experimentation and modelling, Int. J. Mach. Tools Manuf., 53 (2012) 27-38.

[18] M. Elektron, Elektron AZ31B: Sheet, Plate \& Coil, in, Manchester, 2006.

[19] A. Mwembela, E.B. Konopleva, H.J. McQueen, Microstructural development in Mg alloy AZ31 during hot working, Scr. Mater., 37 (1997) 1789-1795. 